\title{
Relationship between Statins Adverse Events and Pharmacokinetic Variables
}

\author{
Cornelli $\mathbf{U}^{1}$, Finco $\mathrm{A}^{2 *}$, Belcaro $\mathrm{G}^{3}$ and Recchia $\mathbf{M}^{4}$ \\ ${ }^{1}$ Loyola University School of Medicine-Chicago, USA \\ ${ }^{2}$ Cor Con International SRL, Ox Res Dept-Parma, Italy \\ ${ }^{3}$ University of Chieti-Pescara, Italy \\ ${ }^{4}$ University of Lugano-Biometrics, Switzerland
}

Submission: February 09, 2018; Published: February 23, 2018

*Corresponding author: Annarosa Finco, Cor Con International Srl- Oxidation Research Department- Parma- Italy, Strada Langhirano 264/1A Parma (PR), Italy, Tel: +39 0521 649157; Email: finco.annarosa@libero.it

Abstract

Background: Statins are a widely used class of drugs very effective in reducing the levels of cholesterol and the mortality for cardiovascular events. Despite these drugs are usually well tolerated, adverse events, such as diabetes type II and myopathy can arise and cause a significant limitation to the therapy adherence. Statins pharmacokinetics (PK) characteristics may have an impact on the determination of these adverse events.

Methods: 14 reviews and 92 papers reporting the PK data were analyzed for the correlation between PK variables and: a) the risk of diabetes type II [DRR] as reported in the Ontario Diabetes Database; b) the myopathies as reported in MAERS (Adverse Events Reporting System between 2005-2011) of FDA. The correlation coefficient " $r$ " and the Ellypses Density were used to calculate the relationship between the variables.

Results: DRR seems to be directly correlated with $\mathrm{t} 1 / 2(\mathrm{r}=0.921 \mathrm{p}<0.05)$ and potency of statins $(\mathrm{r}=0.894 \mathrm{p}<0.05)$, whereas impairment of muscle coordination/weakness seems directly correlated with fecal excretion $(r=0.817 p<0.05)$ mirroring the gastrointestinal recycling. Among the statins pravastatin, lovastatin and fluvastatin were shown safer for the diabetes recurrence and lovastatin was found less myotoxic.

Conclusion: Theoretically for every statin an equilibrium between activity and side effects may exists. Lovastatin seems to be the safer. Since age and concomitant therapies can interfere with PK variables, it is important to reduce the dosage at the minimal effective amount, favoring the bed time administration and the physical exercise.

Keywords : Statins; Myopathy; Diabetes type II; Pharmacokinetics

\section{Introduction}

There are no doubts that statins together with steroids, antibiotics and diuretics are among the most important drugs of the last two centuries. Despite the improvement of the life expectancy, statins have to be used carefully to avoid any misuse that could bring the patients from the benefit to the risk of damaging side effects [1,2].
Statins (hydroxymethyl-glutaryl coenzyme A reductase inhibitors or HMG-CoA reductase inhibitors) are characterized by different potency [3] which is reflected by the daily dosage, ranging between $2 \mathrm{mg}$ (pitavastatin) and $80 \mathrm{mg}$ (fluvastatin), with intermediate dosages of 10,20 and $40 \mathrm{mg}$ respectively for atorvastatin, simvastatin, and lovastatin.

Table 1: Main pharmacokinetics variables of statins and the risk of diabetes and my toxicity.

\begin{tabular}{|c|c|c|c|c|c|c|c|c|c|}
\hline \multirow[t]{2}{*}{ Variable } & \multirow[t]{2}{*}{ Measure } & \multicolumn{8}{|c|}{ Statins } \\
\hline & & Atorva & Ceriva & Fluva & Lova & Pitava $^{\mathrm{e}}$ & Prava & Rosuva & Simva \\
\hline Absorption & \multirow[b]{2}{*}{$\%$} & \multirow[b]{2}{*}{30} & \multirow[b]{2}{*}{98} & \multirow{2}{*}{$90-98$} & \multirow{2}{*}{30} & \multirow[b]{2}{*}{90} & \multirow{2}{*}{$32-35$} & \multirow[b]{2}{*}{50} & \multirow[b]{2}{*}{$70-85$} \\
\hline$(\mathrm{AB})$ & & & & & & & & & \\
\hline Bioavailability & \multirow{2}{*}{$\%$} & \multirow{2}{*}{ Dec- 41} & \multirow{2}{*}{60} & \multirow{2}{*}{$20-25$} & \multirow{2}{*}{5} & \multirow{2}{*}{$51-60$} & \multirow{2}{*}{18} & \multirow{2}{*}{20} & \multirow{2}{*}{5} \\
\hline$(F)$ & & & & & & & & & \\
\hline
\end{tabular}




\section{Modern Applications of Bioequivalence \& Bioavailability}

\begin{tabular}{|c|c|c|c|c|c|c|c|c|c|}
\hline Protein Binding & \multirow{2}{*}{$\%$} & \multirow{2}{*}{$85-98$} & \multirow{2}{*}{99} & \multirow{2}{*}{$98-99$} & \multirow{2}{*}{$80-95$} & \multirow{2}{*}{99} & \multirow{2}{*}{$45-50$} & \multirow{2}{*}{$88-90$} & \multirow{2}{*}{$90-96.5$} \\
\hline$(\mathrm{PB})$ & & & & & & & & & \\
\hline Half Live & \multirow{2}{*}{$\mathrm{h}$} & \multirow{2}{*}{$12.6-32.6$} & \multirow{2}{*}{$2-5^{d}$} & \multirow{2}{*}{$0.75-3$} & \multirow{2}{*}{$1.4-3$} & \multirow{2}{*}{ Jun-14 } & \multirow{2}{*}{$1.6-2$} & \multirow{2}{*}{$19-20.8$} & \multirow{2}{*}{$1.9-5.6$} \\
\hline$\left(\mathrm{T}^{1 / 2}\right)$ & & & & & & & & & \\
\hline Renal Excretion & \multirow{2}{*}{$\%$} & \multirow{2}{*}{$2.3-5$} & \multirow{2}{*}{30} & \multirow{2}{*}{$4.9-6$} & \multirow{2}{*}{$13-30$} & \multirow{2}{*}{15} & \multirow{2}{*}{$20-60$} & \multirow{2}{*}{10} & \multirow{2}{*}{13} \\
\hline (RE) & & & & & & & & & \\
\hline Fecal Elimination & \multirow{2}{*}{$\%$} & \multirow{2}{*}{$70-98$} & \multirow{2}{*}{70} & \multirow{2}{*}{$90-95$} & \multirow{2}{*}{$64-83$} & \multirow{2}{*}{79} & \multirow{2}{*}{$45.5-71$} & \multirow{2}{*}{90} & \multirow{2}{*}{58} \\
\hline (FE) & & & & & & & & & \\
\hline Clearance & J. & 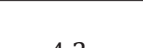 & 20 & $001<0$ & $077_{1}$ & 500 & 112117 & 105 & 75 \\
\hline$(\mathrm{CL} / \mathrm{F})^{\mathrm{A}}$ & $\mathrm{mL} / \mathrm{mIn} / \mathrm{kg}$ & 4.2 & 3.3 & $8.8-16.2$ & $9.7-10$ & $2.5-8$ & 11.3-11.7 & 10.5 & 7.5 \\
\hline Potency $^{\mathrm{b}}$ & & 1 & 0 & مO & 10 & 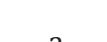 & 10 & $\Gamma$ & 0 \\
\hline$(\mathrm{P})$ & $\mathrm{mg}$ & 10 & 0.3 & 80 & 40 & 2 & 40 & 5 & 20 \\
\hline Risk of Diabetes & Odd ratio & 122 & $N A$ & 095 & 099 & NA & 1 & 118 & 11 \\
\hline (DRR) & & 1.24 & NR & 0.5 & קית & IVA & 1 & 1.18 & 1.1 \\
\hline $\begin{array}{l}\text { Risk of Myopathy } \\
\text { (Maers) }\end{array}$ & Primary $^{c}$ & 58 & NA & 84 & 10 & NA & 21 & 88 & 43 \\
\hline & e values wer & resent in & 4 revi & only ; b=1 & age neec & o obtain & $5 \%$ reducti & LDL; & \\
\hline $\mathrm{c}=$ Primary suspec & $d=$ the refere & $\begin{array}{l}\text { es }(100) \\
-110 \text { sinc }\end{array}$ & $\begin{array}{l}\text { dded } \\
\text { comp }\end{array}$ & $\begin{array}{l}\text { values I } \\
\text { set of dat }\end{array}$ & $\begin{array}{l}\text { rted in } \\
\text { as repor }\end{array}$ & $\begin{array}{l}\text { views; } \\
\text { n one r }\end{array}$ & $\begin{array}{l}\text { values w } \\
\text { only. }\end{array}$ & ken fror & aces 15 , \\
\hline
\end{tabular}

Recently the incidence of side effects, such as diabetes [1] and myopathy [2], have been focused respectively on population based cohort studies for the diabetes risk [DRR] and following a survey of the FDA's Adverse Events Reporting System for Myopathies [MAERs]. In terms of diabetes, pravastatin was taken as the reference drug with DRR = 1 and compared to the other five statins with available risk data. No significant DRR increase was found for lovastatin and fluvastatin, whereas atorvastatin, rosuvastatin, and simvastatin resulted associated with a significantly higher DRR (Table 1).

For the myopathy, MAERs were indicated aligning with potency since rosuvastatin showed the higher risk, atorvastatin and simvastatin intermediate risk, whereas pravastatin and lovastatin appeared to bring the lowest risk rates. No data for DRR and MAERs were available for pitavastatin, whereas cerivastatin was withdrawn from the market few years ago and they were not listed into the published FDA report.

Although the structural characteristics and the metabolic pattern may determine some important difference in the activities of statins, the pharmacokinetics (PK) variables were never taken into account for a systematic analysis of their possible correlation with these two specific side effects. For these reasons we tried to correlate all the most common PK variables with the diabetogenic and myotoxic risk currently available $[1,2]$ for 6 different statins.

\section{Methods}

\section{Data sources}

We have at first analyzed 14 of the published reviews on the PK of statins [4-17] focusing the usual common variables (e.c. absorption, bioavailability, protein binding, see Table 1). Most of the times the half-life of statins reported in the reviews was not differentiating between the lacton and the acidic forms, in particular for lovastatin and simvastatin that may have a different impact on the adverse reactions. For these reasons we re-analyzed 92 publications available on Medline [18-110]. We reviewed also the clearance values (CL/F) that were recalculated for all the products according to a common formula, based upon the non-compartmental methodology and consisting

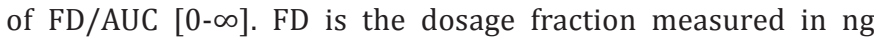
(nanograms) and represented the absorbed quantity of the given statin; AUC $[0-\infty]$ was the area under the plasma curve in terms of $\mathrm{ng} / \mathrm{mL} / \mathrm{h}$. According to this formula, $\mathrm{CL} / \mathrm{F}$ was expressed in $\mathrm{mL} / \mathrm{min} / \mathrm{kg}$. In case the body weight of the subjects was not reported (surprisingly!) a standard body weight of $70 \mathrm{~kg}$ was considered, with the exclusion of Chinese and Corean volunteers for whom the standard body weight was fixed to $60 \mathrm{~kg}$. Since for the majority of the PK trials single data were not available, all the correlations between variables were calculated on the base of the average data. The potency of statins was based upon the dosage to be administered to obtain a similar reduction of LDL as reported in Goodman \& Gliman's “The Pharmacological Basis of Therapeutics" $12^{\text {th }}$ Ed. p.895.

\section{Statistical analysis}

The statistical analysis was based on the correlation coefficient " $r$ " between the PK variables and DRR or MAERs was also applied.

\section{Result}

\section{PK variables}

The PK variables reported on the 14 reviews were summarized in Table 1 . They were related to apparently healthy 
volunteers, following a single administration, and represented the average values or ranges as described in the reviews. Last two rows of the Table 1 report the side effects in terms of DRR for diabetes and MAERs for myotoxicity.

$$
{ }^{\mathrm{a} P}<0.01 ;{ }^{\mathrm{b}} \mathrm{p}<0.05
$$

Absorption [AB];Bioavailability [F]; Protein binding [PB]; Half live [ $\left.\mathrm{t}^{1 / 2}\right]$; Renal excretion [RE]; Fecal elimination [FE]; Clearance [CL/F]; Potency [P]; Risk of diabetes [DRR]; Risk of myopathy [MAERs].

All the reviews indicate that most of the PK variables may change according to age, sex, race, time of administration (morning Vs evening), fasting, and polymorphism. Furthermore, there were also indications that some of the statins were sensible to liver and kidney impairment, and to the concomitant therapies which can interfere because of some metabolic competition.

Potency of statins was considered using as co-variable the dosages equivalent approximately to the $31-35 \%$ reduction of LDL, defining the potency as follows: cerivastatin> pitavastatin > rosuvastatin $>$ atorvastatin $>$ simvastatin $>$ pravastatin=lovastatin $>$ fluvastatin.

The correlation matrix is reported in Table 2 and was based upon the average data listed in Table 1. For those variables consisting of range values, the average value was taken as covariate for the calculations. Some of the correlations were statistically significant, both with positive (direct) and negative (indirect) values and the signs were most of the time coherent. The following indications can be drawn:

Table 2: Correlations ("r") between pharmacokinetics variables of statins and diabetes risk (DRR) or Adverse Events Report System (MAERs). Values correspond to "r".

\begin{tabular}{|c|c|c|c|c|c|c|c|c|c|c|}
\hline & $\mathrm{AB}$ & $\mathbf{F}$ & PB & $t^{1 / 2}$ & RE & FE & CL & $\mathbf{P}$ & DRR & MAERs \\
\hline $\mathrm{AB}$ & 1 & -0.042 & 0.499 & -0.352 & -0.44 & 0.239 & 0.184 & 0.545 & -0.334 & 0.577 \\
\hline $\mathrm{F}$ & & 1 & 0.002 & 0.569 & -0.302 & 0.701 & -0.098 & 0.084 & 0.24 & 0.496 \\
\hline $\mathrm{PB}$ & & & 1 & 0,269 & $-0.924^{a}$ & 0.599 & -0.455 & 0.008 & 0.242 & 0.536 \\
\hline $\mathrm{t} 1 / 2$ & & & & 1 & -0.537 & 0.497 & -0.682 & -0.724 & $0.921^{\mathrm{a}}$ & 0.496 \\
\hline $\mathrm{RE}$ & & & & & 1 & -0.714 & -0.595 & 0.109 & -0.462 & -0.728 \\
\hline $\mathrm{FE}$ & & & & & & 1 & -0.062 & 0.141 & 0.188 & 0.755 \\
\hline CL & & & & & & & 1 & 0.636 & -0.806 & -0.149 \\
\hline $\mathrm{P}$ & & & & & & & & 1 & $-0.894^{\mathrm{a}}$ & -0.009 \\
\hline DRR & & & & & & & & & 1 & 0.355 \\
\hline MAERs & & & & & & & & & & 1 \\
\hline
\end{tabular}

1. the inverse relationship between $\mathrm{RE}$ and $\mathrm{PB}$ was significant $(p<0.01)$ indicating that the renal excretion of statins is limited by the PB;

2. the DRR was directly correlated with the $t 1 / 2(0.921$; $\mathrm{p}<0.01$ ) standing for a more pronounced diabetogenic tendency in relation to the drug permanence in the plasma;

3. DRR showed a direct correlation with potency also $(-0.894 ; \mathrm{p}<0.05)$, the negative value was because the covariate was the dosage;

4. despite RE and FE were not significantly correlated with MAERs, the values (respectively -0.728 and 0.755 ) were close to be significant $(\mathrm{p}<0.07)$;

5. the analysis of myotoxicity in relation to $\mathrm{FE}$ was extended to every symptom using as covariate the primary AEs as they were reported in the FDA's database (see Table 3);

Table 3: Correlations ( $r$ ) between fecal excretion (FE) and primary MAERs of FDA database related to statins drug class.

6

\begin{tabular}{|c|c|c|c|c|c|c|c|}
\hline & Atorva & Fluva & Lova & Prava & Rosu & Simva & R Vs FE \\
\hline Myalgia & 57 & 69 & 5 & 20 & 100 & 18 & 0,802 \\
\hline Myopathy & 67 & 100 & 17 & 21 & 78 & 54 & 0,738 \\
\hline Myositis & 63 & 91 & 7 & 25 & 81 & 100 & 0,284 \\
\hline Rhabdomyolysis & 38 & 100 & 14 & 16 & 91 & 18 & 0,549 \\
\hline Joints \& Tendoms & 56 & 60 & 8 & 18 & 100 & 0,790 \\
\hline Muscle Atrophy & 73 & 100 & 10 & 31 & 69 & 24 & 0,804 \\
\hline Muscle Coord/Weak* & 51 & 68 & 7 & 14 & 100 & 18 & $0,817^{\mathrm{a}}$ \\
\hline
\end{tabular}


6. among the various MAERs only muscle coordination and weakness was found significantly correlated with FE, whereas myalgia, myopathy, joint \& tendom, muscle atrophy were close to be significant ( $r$ between 0.738 and 0.804 $\mathrm{p}<0.07$ ), and myositis and rabdomyolysis were found to be independent;

7. The same analysis was conducted for UE (data not reported), and for myalgia only an inverse correlation was found close to the statistical significance $(r-0.809 \mathrm{p}<0.06)$.

As usual, FE was expressed as \% of the product that was absorbed and then excreted through the bile into the intestine.
In kinetics terms this excretion should be part of the total CL which essentially is the combination of the renal and hepatic clearances. The lack of correlation between CL values and both DRR and MAERs was considered as a discrepancy, and stimulated the re-analysis of almost all PK data published (abstract were excluded).

Among all the studies [18-110] only those reporting PK data pertinent to the original product and/or lacton plasma levels were analyzed (see Table 4). In the reviewed studies there was a large prevalence of males (678 $\mathrm{M}$ and $311 \mathrm{~F}$ ) for all statins, with the exclusion of pravastatin (139 M; $114 \mathrm{~F}$ ). The body weight and age range were almost similar for all the products (see Table 4).

Table 4: PK general characteristics of the pertinent original statins (as acid/lacton).

\begin{tabular}{|c|c|c|c|c|c|c|}
\hline Statin & $\underset{\mathrm{kg}}{\mathrm{CL} / \mathrm{F} \text { a } \mathrm{mL} / \mathrm{min} /}$ & $t^{1 / 2} h$ & $\mathrm{~N}$ of trials (references) & $\mathrm{N}$ of cases $(\mathrm{M} ; \mathrm{F})$ & $\begin{array}{c}\text { mean age } \\
\text { range } \\
\text { (years) }\end{array}$ & $\begin{array}{c}\text { Mean BW } \\
\text { range (kg) }\end{array}$ \\
\hline Atorva acid & \multirow[b]{2}{*}{$22 \pm 9.2$} & $9.5 \pm 3.72$ & 4 & \multirow[b]{2}{*}{$48(35 \mathrm{M} ; 13 \mathrm{~F})$} & \multirow[b]{2}{*}{$23-35$} & \multirow[b]{2}{*}{$67-77$} \\
\hline Atorva lacton & & $10.4 \pm 3.31$ & $(18,19,23,26)$ & & & \\
\hline Fluva acid & $31 \pm 16.4$ & $1.8 \pm 1.14$ & $10(31-40)$ & $20(137 \mathrm{M} ; 66 \mathrm{~F})$ & $22-65$ & $65-75$ \\
\hline Lova lacton & \multirow{2}{*}{$34 \pm 22.8$} & $2.9 \pm 1.43$ & $14(20,42-47,49$ & \multirow{2}{*}{239 (173 M; 66 F) } & \multirow{2}{*}{$22-65$} & \multirow{2}{*}{$64-73$} \\
\hline Lova acid & & $2.6 \pm 0.48$ & $51,52,55-58)$ & & & \\
\hline Prava acid & $25 \pm 13.8$ & $2.0 \pm 1.11$ & $\begin{array}{c}14(19,26,31,34 \\
41,48,50,60,61 \\
65,67,68,70,71)\end{array}$ & $280(150 \mathrm{M} ; 130 \mathrm{~F})$ & $22-79$ & $56-82$ \\
\hline Rosuva acid & $22 \pm 13.8$ & $16.3 \pm 5.33$ & $14(58,72-79,81-85)$ & $184(157$ M; 27 F) & $24-49$ & $59-87$ \\
\hline Simva lacton & \multirow{2}{*}{$124 \pm 48.1$} & $2.8 \pm 0.80$ & 9 & 100 & $22-51$ & $62-84$ \\
\hline Simva acid & & $3.1 \pm 0.51$ & $(67,86-92)$ & $(61 \mathrm{M} ; 39 \mathrm{~F})$ & & \\
\hline
\end{tabular}

a) The CL/F was calculated on the base of the average "absorbed dosage" (as reported in Table 1): in the general formula: FD/AUC. AUCs of atorvastatin, lovastatin and simvastatin were represented by the sum of lacton and acid area.

b) $60 \mathrm{Kg}$ were taken as a standard value for trials conducted in China and Corea that were not indicating the body weight, in all the other studies not reporting the body weight $70 \mathrm{~kg}$ were taken as standard value.

Some discrepancies were found between the values reported in the reviews and our calculations. In particular the half life of atorvastatin and rosuvastatin resulted much lower than those indicated by the other authors (reported in Table 1). For atorvastatin, the averages of our analysis were 9.5$10.4 \mathrm{~h}$ respectively for acid and lacton, whereas a combined range between 12.6 and $32.6 \mathrm{~h}$ was found in the reviews. For rosuvastatin the average value in our analysis was $16.3 \mathrm{~h}$ compared to a range of $19-20.8 \mathrm{~h}$ of the reviews. However, even considering our data the correlation between DRR and half life still remained significant $(0.835 \mathrm{p}<0.05)$.
The highest discrepancy came out from the CL values. This was because our calculations were based upon the average "absorbed dosage" (see Table 1) that end up with higher values than those calculated using the bioavailable dosage. In any case, the correlation between our CL values and both DRR and MAERs did not became significant.

\section{Discussion}

Despite many limitations, some practical indications came out from this analysis:

1. The power of statins is correlated with the diabetogenic side effects

2. the diabetogenity is in relation to a longer half life

3. The impairment of muscle coordination and weakness are correlated to the fecal excretion.

The first point doesn't need much explanation, since this side effects can be taken as part of the pleiotropic effects of statins that basically are all dose related. However, lovastatin came out to be less toxic than the other statins although it can 
reduce cholesterol levels in the same way. This indicates that an equilibrium exists between activity and side effects that theoretically can be found for every statin.

The second point indicates that product with longer half live (atorvastatin and rosuvastatin) can cause diabetes II with relatively higher frequency than short half life statins. This can be due in part to some accumulation of the drug following repeated administration. Lipophilic molecules represented by the lactonic form can have a more consistent penetration in the tissues than the acidic moieties The more diabetogenic statins such as atorvastatin and rosuvastatin, despite administered as acidic forms were shown to be transformed into the lactonic forms that usually are characterized by a longer half life than the parent drug. This last point is consistent with the long permanence in the liver and other tissue (as muscles and pancreas) that may be determinant for this specific side effect.

The relationship between fecal excretion and myotoxicity needs a more complex "explanatory hypothesis". During the first pass effect, both the intestine and the liver acting as a barrier do not allow the given statin to reach the circulation. However, the product cannot flow immediately into the liver because the enterocytes takes up part of the drug, and then they release it back to the intestinal fluid (apparently as it happens with phytosterols). The consequence of this "cycling" is such that the statin will be theoretically absorbed diffusing within the intestine without reaching the liver. The part of the statin crossing the intestine and getting to the liver can follow four ways only: part will inhibit the HMG-CoA reductase, part will be metabolized (via CYPs or other pathways such as sulfation), part will be "exported" in the tissues, and all the remaining part (free or bound to the bile salts) will be excreted via the biliary system into the gut. Once in the intestine the statin and/or the metabolites can be reabsorbed for a "second" first pass effect, recycling between and gut and liver.

In a different perspective, the fecal excretion mirrors the gut/liver recycle and the gut/liver metabolic burden also. This "circle" cannot be picked up by the classical CL measurement that stands for the amount of blood cleared out from the drug (in $\mathrm{mL} / \mathrm{min} / \mathrm{kg}$ or equivalents), simply because the product doesn't arrive to the extra-hepatic circulation.

This could mean that myotoxicity and diabetogenic tendency belong to the liver/gut burden mainly and only to the concentration in muscles and pancreas. For what concerns cerivastatin, one may say that its potency could give some suspect about the diabetogenicity, but fecal excretion was not higher that other safer statins and consequently myotoxicity should not be more prominent than with the other statins. This may indicate that, as supposed by many authors, the interference with the concomitant therapies such as gemfibrozil could be the cause of rabdomyolysis and other myotoxic symptoms.

Pitavastatin is lacking of monitoring data on both diabetes and myotoxicity. The potency and the relative long half-life of the product may give some suspect for diabetes, whereas in terms of MAERs the fecal excretion seems to be close the one observed for safer statins.

\section{Indications for the Therapy with Statins}

One may not argue about the activity of statins or about their efficacy in controlling cardiovascular events. The arguments concerning primary or secondary prevention of cardiovascular diseases has been clarified in hundred of clinical trial, and doctors can easily tailor any statin to the patient's need [93]. The real threat of statins is the misuse, and the relative side effects cannot be denied. The risk benefit ratio could be improved substantially if the patient's therapy will follows some very simple rules.

Because of the underlined mechanisms of toxicity, the suggestions for the doctors could be: a) to reduce the dosage as much as possible; b) to give the treatment in the evening (cholesterol synthesis is peaking between midnight and the first hours of the morning), no matter if in some author was showing that the evening and morning administration end up with identical activity. The evening administration (just before sleeping) will have a favorable impact on oxidative stress. During sleep the oxidative stress become minimal, and the liver, the gut, and all the tissues interested by the statin's pleiotropic effect can use their metabolic energy to get a rid of the drug excess and relative toxic metabolites. Finally the gut/liver recycle will be minimal for the reduction of bile secretion.

Similarly, physical exercise will improve the antioxidant defense, since trained muscles are extremely efficient in producing enzymatic antioxidants that can help in controlling the oxidative stress deriving from the statin's metabolic burden. According to the evening scheme of treatment, the morning intake of grape fruit juice should not compromise the plasma levels of statins with short half live (fluvastatin, lovastatin, pravastatin, simvastatin).

There are also alternative therapies based upon the lovastatin, that was found to be safer than the other statins, but still may have same side effects. Lovastatin can be administered as a "food supplement" in formulations containing Monascus purpureus [94-97]. However, doctors have to prescribe the product (not TV or advertising) and should be minded to give dosages (in the evening) not exceeding $10 \mathrm{mg}$ /day of monakolin $\mathrm{K}$ (which is lovastatin). Furthermore, products containing Monascus $p$. plus berberine should be avoided, since the latter has about $30 \mathrm{~h}$ of half-life [98], tends to accumulate following repeated administration, and can be potentially toxic [99].

\section{Limitations and Strengths}

The main limitation of this study was that all the variables reported consist of average values. The use of average values does not allow to determine the variance, which was quite large for all the products. The PK variances of statins suffer of multiple interferences for absorption, transportation in and out of the liver, polymorphism, and finally for the involvement 
of different CYPs. During the analysis we have noted that differences on the variables can derive also from morning and evening administration, fasting, age and sex. The race difference is also known, particularly for some Asiatic people that need to be treated with lower dosages. Furthermore, most of the studies were conducted in healthy volunteers and the concomitant therapies may have an important impact on the PK variables. However, these were the same problems that had to be faced by the authors of the 14 reviews.

Some of PK data reported in the literature of the seven statins were lacking of important information such as body weight of volunteers, and the measure of the apparent distribution volumes (VD) was very rare for all the products and impossible to be re-calculated. This last point was due to the lack of the values of the drug absorption (for pitavastin was not reported in any paper), and because the data on plasma concentrations were presented only as figures and not as values.

In same study was also difficult to end up with precise calculation of AUC [o to infinity], particularly for those statins with higher half-life. Since the CL measure belongs to the ratio D/AUC, sometimes was hard to make a precise determination of AUC $[[0-\infty]$ that in our calculations may contain estimation errors up the $10 \%$. However, even an errors up to $10 \%$ of AUC will not change the CL in a sensible way.

Another limitation belongs to the different methodology used both for chemical analysis of the same statin (inter-laboratory variations), for the blood sampling time (sometimes to short) and for the evaluation of PK variables that were calculate applying different models (compartmental or non-compartmental). However, the variable we used for the reanalysis ( $\mathrm{t}^{1 / 2}$ and AUC) were very solid and made our evaluation sufficiently precise.

The few number of correlation couples available, 6 points only, implies that data have to be considered carefully. In the future the side effect records with pitavastatin (in case they will appear) may improve the power of the correlations. The strength of the study was the complete review of most of the available PK data on statins. At the end of the analysis we were wandering if doctors that are not very well skilled in PK can come out from the fog generated by all the information given that sometimes is redundant, and with no practical explanation. This could mean that the doctor has to relay on his experience only, no matter about polymorphisms and drug interferences, that although important, most of the time seem more oriented to the commercial differentiation.

\section{References}

1. Carter AA, Gomes T, Camacho X, David NJ, Baiju RS, et al. (2013) Risk of incident diabetes among patients treated with statins: population based study. BMJ 346: f2610.

2. Hoffman KB, Kraus C, Dimbil M, Beatrice AG (2012) A survey of the FDA's Database regarding muscle and tendon adverse events linked to the statin drug class. PLOS 7: e42866.
3. Bersot TP (2011) Drug therapy for hypercholesterolemia and dyslipidemia. In: (12 $2^{\text {th }}$ edn), in The Pharmacological Basis of Therapeutics, Goodman \& Gillman's, USA, p. 894.

4. Jacobson TA (2009) Myopathy with statin-fibrate combination therapy: clinical consideration. Nat Rev Endocrinol 5: 507-518.

5. Neuvonen PJ, Backman JT, Niemi M (2008) Pharmacokinetic comparison of the potential Over-the-Counter statins simvastatin, lovastatin, fluvastatin ans pravastatin. Clin Pharmacokinet 47(7): 463-474.

6. Bays HE, Dujovne CA (1998) Drug interaction of lipid-altering drugs. Drug safety 19(5): 355-371.

7. William D, Feely J (2002) Pharmacokinetic-Pharmacodynamic drug interactions with HMG-CoA reductase inhibitors. Clin Pharmacokinet 41(5): 343-370.

8. Baer AN, Wortmann RL (2007) Myotoxicity associated with lipid-lowering drugs. Current Opin Rheumatol 19(1): 67-73.

9. Desager JP, Horsmans Y (1996) Clinical Pharmacokinetics of 3-Hydroxy-3-Methylglutaryl-Coenzyme A reductase inhibitors. Clin Pharmacokinet 31(5): 348-371.

10. Bottorf M, Hansten P (2000) Long-term safety of hepatic Hydroxymethyl Glutaryl Coenzyme A reductase inhibitors: the role of metabolism-monograph for physicians. Arch Int Med 160(15): 2273-2280.

11. Schachter M (2004) Chemical, pharmacokinetic and pharmacodynamic properties of statins: an update. Clin Pharmacol 19(1): 117-125.

12. Bellosta S, Paoletti R, Corsini A (2004) Safety of statins: focus on clinical pharmacokinetics and drug interaction. Circulation 109(23 suppl 1): $50-57$.

13. Corsini A, Bellosta S, Baetta R, Fumagalli R, Paoletti R, et al. (1999) New insight into the pharmacodynamic and pharmacokinetic properties of statins. Parmacol \& Therap 84(3): 413-428.

14. Lennernäs FG (1997) Pharmacodynamic and pharmacokinetics of the HMG-CoA Reductase inhibitors: similarities and differences. Clin Pharmocokinet 32(5): 403-425.

15. Garcia MJ, Reinoso RF, Sanchez NA, Prous JR (2003) Clinical pharmacokinetics of statins. Methods Find Exp Clin Pharmacol 25(6): 457-481.

16. Lea AP, Tavish MD (1997) Atorvastatin: a review of its pharmacology and therapeutics potential in the management of hyperlipidaemia. Drug 53(5): 828-847.

17. Duggan DE, Vickers S (1990) Physiological disposition of HMG-VCoA reductase inbhibitors. Drug metab Reviews 22(4): 333-362.

18. Kantola T, Kivistö KT, Neuvonen PJ (1998) Effect of itraconazole on the pharmacokinetics of atorvastatin. Clin Pharmacol Ther 64(1): 58-65.

19. Mazzu AL, Lasseter KC, Shamblen EC, Agarwal V, Lettieri J, et al. (2000) Itraconazole alters the pharmacokinetics of atorvastatin to a greater extent than either cerivastatin or pravastatin. Clin Pharmacol Ther 68(4): 391-400.

20. Cilla DD, Gibson DM, Whitfield LR, Sedman AJ (1996) Pharmacodynamic effects and pharmacokinetics of atorvastatin after administration to normocholesterolemic subjects in the morning and evening. J Clin Pharmacol 36(7): 604-609.

21. Posvar EL, Radulovic LL, Cilla DD, Whitfield LR, Sedman AJ, et al. (1996) Tolerance and pharmacokinetics of single-dose atorvastatin, a potent inhibitor of HMG-CoA reductase, in healthy subjects. J Clin Pharmacol 36(8): 728-731.

22. Radulovic LL, Cilla DD, Posvar EL, Sedman AJ, Whitfield LR, et al. (1995) Effect of food on the bioavailability of atorvastatin, an HMG-CoA reductase inhibitor. J Clin Pharmacol 35(10): 990-994.

23. Ando H, Tsuruoka S, Yanagihara H, Koh-ichi S, Masaaki M, et al. (2005) Effects of grapefruit juice on the pharmacokinetics of pitavastatin and atorvastatin. Br J Clin Pharmacol 60(5): 494-497. 
24. Gibson DM, Bron NJ, Richens A, Hounslow NJ, Sedman AJ, et al. (1996) Effect of age and gender on pharmacokinetics of atorvastatin in humans. J Clin Pharmacol 36(3): 242-246.

25. Gajula R, Pilli NR, Ravi VB, Rambabu M, Jaswanth KI, et al. (2012) Simultaneous Determination of Atorvastatin and Aspirin in Human Plasma by LC-MS/MS: Its Pharmacokinetic Application. Sci Pharm 80(4) 923-940.

26. Lilja JJ, Kivistö KT, Neuvonen PJ (1999) Grapefruit juice increases serum concentrations of atorvastatin and has no effect on pravastatin. Clin Pharmacol Ther 66(2): 118-127.

27. Cilla DD, Whitfield LR, Gibson DM, Sedman AJ, Posvar EL, et al. (1996) Multiple-dose pharmacokinetics, pharmacodynamics, and safety of atorvastatin, an inhibitor of HMG-CoA reductase, in healthy subjects Clin Pharmacol Ther 60(6): 687-695.

28. Kandhwal K, Dey S, Nazarudheen S, Arora R, Reyar S, et al. (2011) Pharmacokinetics of a fixed-dose combination of atorvastatin and metformin extended release versus concurrent administration of individual formulations: a randomized, open-label, two-treatment, two-period, two-sequence, single-dose, crossover, bioequivalence study. Clin Drug Investig 31(12): 853-863.

29. Chong PH, Seeger JD (1997) Atorvastatin calcium: an addition to HMGCoA reductase inhibitors. Pharmacotherapy 17(6): 1157-1177.

30. Stern RH, Yang BB, Horton M, Moore S, Abel RB, et al. (1997) Renal dysfunction does not alter the pharmacokinetics or LDL-cholesterol reduction of atorvastatin. J Clin Pharmacol 37(9): 816-819.

31. Kantola T, Backman JT, Niemi M, Kivistö KT, Neuvonen PJ, et al. (2000) Effect of fluconazole on plasma fluvastatin and pravastatin concentrations. Eur J Clin Pharmacol 56(3): 225-229.

32. Smith HT, Jokubaitis LA, Troendle AJ, Hwang DS, Robinson WT, et al. (1993) Pharmacokinetics of fluvastatin and specific drug interactions. Am J Hypertens 6(11 pt 2): 375S-382S.

33. Tse FL, Jaffe JM, Troendle A (1992) Pharmacokinetics of fluvastatin after single and multiple doses in normal volunteers. J Clin Pharmacol 32(7): 630-638.

34. Keskitalo JE, Pasanen MK, Neuvonen PJ, Niemi M (2009) Different effects of the ABCG2 c.421C>A SNP on the pharmacokinetics of fluvastatin, pravastatin and simvastatin. Pharmacogenomics 10(10): 16171624.

35. Appel S, Dingemanse J (1996) Clinical pharmacokinetics of fluvastatin with reference to other reductase inhibitors. Drugs today 32: 37-55.

36. Scripture CD, Pieper JA (2001) Clinical pharmacokinetics of fluvastatin. Clin Pharmacokinet 40(4): 263-281.

37. Kivistö KT, Kantola T, Neuvonen PJ (1998) Different effects of itraconazole on the pharmacokinetics of fluvastatin and lovastatin. Br J Clin Pharmacol 46(1): 49-53.

38. Transon C, Leemann T, Vogt N, Dayer P (1995) in vivo inhibition profile of cytochrome P450TB (CYP2C9) by (+/-)-fluvastatin. Clin Pharmacol Ther 58(4): 412-417.

39. Xu HR, Chen WL, Chu NN, Li XN, Zhu JR, et al. (2012) The difference in pharmacokinetics and pharmacodynamics between extended-release fluvastatin and immediate-release fluvastatin in healthy Chinese subjects. J Biomed Biotechnol, p. 386230.

40. Smith HT, Jokubatis LA, Troendle AJ, Hwang DS, Robinson WT, et al. (1993) Pharmacokinetics of fluvastatin and specific drug interaction. Am J Hypert 6(11 pt 2): 375S-382S.

41. Pentikainen PJ, Saraheimo M, Schwartz JI, Amin RD, Schwartz MS, et al (1992) Comparative pharmacokinetics of lovastatin, simvastatin and pravastatin in humans. J Clin Pharmacol 32(2): 136-140.
42. Kyrklund C, Backman JT, Kivistö KT, Neuvonen M, Laitila J, et al. (2001) Plasma concentrations of active lovastatin acid are markedly increased by gemfibrozil but not by bezafibrate. Clin Pharmacol Ther 69(5): 340345 .

43. Mignini F, Tomassoni D, Streccioni V, Traini E, Amenta F, et al. (2008) Pharmacokinetics and bioequivalence study of two tablet formulations of lovastatin in healthy volunteers. Clin Exp Hypertens 30(2): 95-108.

44. Sun JX, Niecestro R, Phillips G, Shen J, Lukacsko P, et al. (2002) Comparative pharmacokinetics of lovastatin extended-release tablets and lovastatin immediate-release tablets in humans. J Clin Pharmacol 42(2): 198-204.

45. Chen CH, Uang YS, Wang ST, Jyh-Chin Y, Chun-Jung L, et al. (2012) Interaction between Red Yeast Rice and CYP450 Enzymes/P-Glycoprotein and Its Implication for the Clinical Pharmacokinetics of Lovastatin. Evid Based Complement Alternat Med, p. 10.

46. Li Z, Seeram NP, Lee R, Thames G, Minutti C, et al. (2005) Plasma clearance of lovastatin versus chinese red yeast rice in healthy volunteers. J Altern Complement Med 11(6): 1031-1038.

47. Kantola T, Kivistö KT, Neuvonen PJ (1998) Grapefruit juice greatly increases serum concentrations of lovastatin and lovastatin acid. Clin Pharmacol Ther 63(4): 397-402.

48. Pan HY, Triscari J, DeVault AR, Smith SA, Wang-Iverson D, et al. (1991) Pharmacokinetic interaction between propranolol and the HMG-CoA reductase inhibitors pravastatin and lovastatin. Br J Clin Pharmacol 31(6): 665-670.

49. Rogers JD, Zhao J, Liu L, Amin RD, Gagliano KD, et al. (1999) Grapefruit juice has minimal effects on plasma concentrations of lovastatin-derived 3-hydroxy-3-methylglutaryl coenzyme A reductase inhibitors. Clin Pharmacol Ther 66(4): 358-366.

50. Azie NE, Brater DC, Becker PA, Jones DR, Hall SD, et al. (1998) The interaction of diltiazem with lovastatin and pravastatin. Clin Pharmacol Ther 64(4): 369-377

51. Bramer SL, Brisson J, Corey AE, Mallikaarjun S (1999) Effect of multiple cilostazol doses on single dose lovastatin pharmacokinetics in healthy volunteers. Clin Pharmacokinet 37(Suppl 2): 69-77.

52. Vree TB, Dammers E, Ulc I, Horkovics-Kovats S, Ryska M, et al. (2003) Differences between lovastatin and simvastatin hydrolysis in healthy male and female volunteers: gut hydrolysis of lovastatin is twice that of simvastatin. Scientific World Journal 11(3): 1332-1343.

53. Pan HY, DeVault AR, Wang-Iverson D, Ivashkiv E, Swanson BN, et al. (1990) Comparative pharmacokinetics and pharmacodynamics of pravastatin and lovastatin. J Clin Pharmacol 30(12): 1128-1135.

54. Quérin S, Lambert R, Cusson JR, et al. (1991) Single-dose pharmacokinetics of 14C-lovastatin in chronic renal failure. Clin Pharmacol Ther 50(4): 437-441.

55. Reyderman L, Kosoglou T, Boutros T, Seiberling M, Statkevich P, et al. (2004) Pharmacokinetic interaction between ezetimibe and lovastatin in healthy volunteers. Curr Med Res Opin 20(9): 1493-500.

56. Donovan JM, Kisicki JC, Stiles MR, Tracewell WG, Burke SK, et al. (2002) Effect of colesevelam on lovastatin pharmacokinetics. Ann Pharmacother 36(3): 392-397.

57. Bucher M, Mair G, Kees F (2002) Effect of roxithromycin on the pharmacokinetics of lovastatin in volunteers. Eur J Clin Pharmacol 57(11): 787-791.

58. Keskitalo JE, Kurkinen KJ, Neuvonen M, Janne TB, Neuvonen PJ, et al. (2009) No significant effect of ABCB1 haplotypes on the pharmacokinetics of fluvastatin, pravastatin, lovastatin, and rosuvastatin. Br J Clin Pharmacol 68(2): 207-213. 
59. Duggan DE, Chen IW, Bayne WF, Halpin RA, Duncan CA, et al. (1989) The physiological disposition of lovastatin. Drug Metab Dispos 17(2): 166-173.

60. Pan HY, Waclawski AP, Funke PT, Whigan D (1993) Pharmacokinetics of pravastatin in elderly versus young men and women. Ann Pharmacother 27(9): 1029-1033.

61. Triscari J, Swanson BN, Willard DA, Cohen AI, Devault A, et al. (1993) Steady state serum concentrations of pravastatin and digoxin when given in combination. Br J Clin Pharmacol 36(3): 263-265.

62. Tavish MD, Sorkin EM (1991) Pravastatin. A review of its pharmacological properties and therapeutic potential in hypercholesterolaemia. Drugs 42(1): 65-89.

63. Hatanaka T (2000) Clinical pharmacokinetics of pravastatin: mechanisms of pharmacokinetic events. Clin Pharmacokinet. 39(6): 397-412.

64. Quion JA, Jones PH (1994) Clinical pharmacokinetics of pravastatin. Clin Pharmacokinet 27(2): 94-103.

65. Singhvi SM, Pan HY, Morrison RA, Willard DA (1990) Disposition of pravastatin sodium, a tissue-selective HMG-CoA reductase inhibitor, in healthy subjects. Br J Clin Pharmacol 29(2): 239-243.

66. Pan HY, DeVault AR, Brescia D, Willard DA, McGovern ME, et al. (1993) Effect of food on pravastatin pharmacokinetics and pharmacodynamics. Int J Clin Pharmacol Ther Toxicol 31(6): 291-294.

67. Sugimoto K, Ohmori M, Tsuruoka S, Nishiki K, Kawaguchi A, et al. (2001) Different effects of St John's wort on the pharmacokinetics of simvastatin and pravastatin. Clin Pharmacol Ther 70(6): 518-524.

68. Kyrklund C, Backman JT, Neuvonen M, Neuvonen PJ (2003) Gemfibrozil increases plasma pravastatin concentrations and reduces pravastatin renal clearance. Clin Pharmacol Ther 73(6): 538-544.

69. Pan HY, DeVault AR, Swites BJ, Whigan D, Ivashkiv E, et al. (1990) Pharmacokinetics and pharmacodynamics of pravastatin alone and with cholestyramine in hypercholesterolemia. Clin Pharmacol Ther 48(2): 201-207.

70. Sigurbjörnsson S, Kjartansdóttir T, Jóhannsson M, Kristinsson J, Sigurdsson G, et al. (1998) A pharmacokinetic evaluation of pravastatin in middle-aged and elderly volunteers. Eur J Drug Metab Pharmacokinet 23(1): 13-18.

71. Halstenson CE, Triscari J, DeVault A, Shapiro B, Keane W, et al. (1992) Single-dose pharmacokinetics of pravastatin and metabolites in patients with renal impairment. J Clin Pharmacol 32(2): 124-132.

72. Cooper KJ, Martin PD, Dane AL, Warwick MJ, Schneck DW, et al. (2002) The effect of fluconazole on the pharmacokinetics of rosuvastatin. Eur J Clin Pharmacol 58(8): 527-531.

73. Martin PD, Warwick MJ, Dane AL, Brindley C, Short T, et al. (2003) Absolute oral bioavailability of rosuvastatin in healthy white adult male volunteers. Clin Ther 25(10): 2553-2563.

74. Martin PD, Warwick MJ, Dane AL, Hill SJ, Giles PB, et al. (2003) Metabolism, excretion, and pharmacokinetics of rosuvastatin in healthy adult male volunteers. Clin Ther 25(11): 2822-2835.

75. Cooper KJ, Martin PD, Dane AL, Warwick MJ, Raza A, et al. (2003) Lack of effect of ketoconazole on the pharmacokinetics of rosuvastatin in healthy subjects. Br J Clin Pharmacol 55(1): 94-99.

76. Zhou Q, Ruan ZR, Yuan H, Xu DH, Zeng S, et al. (2013) ABCB1 gene polymorphisms, ABCB1 haplotypes and ABCG2 c.421c > A are determinants of inter-subject variability in rosuvastatin pharmacokinetics. Pharmazie 68(2): 129-134

77. Cooper KJ, Martin PD, Dane AL, Warwick MJ, Raza A, et al. (2003) The effect of erythromycin on the pharmacokinetics of rosuvastatin. Eur J Clin Pharmacol 59(1): 51-56.
78. Simonson SG, Martin PD, Mitchell P, Schneck DW, Lasseter KC, et al. (2003) Pharmacokinetics and pharmacodynamics of rosuvastatin in subjects with hepatic impairment. Eur J Clin Pharmacol 58(10): 669675.

79. Deng JW, Shon JH, Shin HJ, Park SJ, Yeo CW, et al. (2008) Effect of silymarin supplement on the pharmacokinetics of rosuvastatin. Pharm Res 25(8): 1807-1814.

80. Tzeng TB, Schneck DW, Birmingham BK, Mitchell PD, Zhang H, et al. (2008) Population pharmacokinetics of rosuvastatin: implications of renal impairment, race, and dyslipidaemia. Curr Med Res Opin 24(9): $2575-2585$.

81. Martin PD, Warwick MJ, Dane AL, Cantarini MV (2003) A double-blind, randomized, incomplete crossover trial to assess the dose proportionality of rosuvastatin in healthy volunteers. Clin Ther 25(8): 2215-2224.

82. Li Y, Jiang X, Lan K, Zhang R, Li X, et al. (2007) Pharmacokinetic properties of rosuvastatin after single-dose, oral administration in Chinese volunteers: a randomized, open-label, three-way crossover study. Clin Ther 29(10): 2194-2203.

83. Martin PD, Mitchell PD, Schneck DW (2002) Pharmacodynamic effects and pharmacokinetics of a new HMG-CoA reductase inhibitor, rosuvastatin, after morning or evening administration in healthy volunteers. Br J Clin Pharmacol 54(5): 472-477.

84. Li XN, Xu HR, Chen WL, Chu NN, Zhu JR, et al. (2010) Pharmacokinetics of rosuvastatin in healthy Chinese volunteers living in China: a randomized, open-label, ascending single- and multiple-dose study. Clin Ther 32(3): 575-587.

85. Cooper KJ, Martin PD, Dane AL, Warwick MJ, Schneck DW, et al. (2003) The effect of itraconazole on the pharmacokinetics of rosuvastatin. Clin Pharmacol Ther 73(4): 322-329.

86. Backman JT, Kyrklund C, Kivistö KT, Wang JS, Neuvonen PJ, et al. (2000) Plasma concentrations of active simvastatin acid are increased by gemfibrozil. Clin Pharmacol Ther 68(2): 122-129.

87. O’Brien SG, Meinhardt P, Bond E, Beck J, Peng B, et al. (2003) Effects of imatinib mesylate (STI571, Glivec) on the pharmacokinetics of simvastatin, a cytochrome p450 3A4 substrate, in patients with chronic myeloid leukaemia. Br J Cancer 89(10): 1855-1859.

88. Mousa O, Brater DC, Sunblad KJ, Hall SD (2000) The interaction of diltiazem with simvastatin. Clin Pharmacol Ther 67(3): 267-274.

89. Pasanen MK, Neuvonen M, Neuvonen PJ, Niemi M (2006) SLC01B1 polymorphism markedly affects the pharmacokinetics of simvastatin acid. Pharmacogenet Genomics 16(12): 873-879.

90. Lilja JJ, Neuvonen M, Neuvonen PJ (2004) Effects of regular consumption of grapefruit juice on the pharmacokinetics of simvastatin. Br J Clin Pharmacol 58(1): 56-60.

91. Lilja JJ, Kivistö KT, Neuvonen PJ (1998) Grapefruit juice-simvastatin interaction: effect on serum concentrations of simvastatin, simvastatin acid, and HMG-CoA reductase inhibitors. Clin Pharmacol Ther 64(5): 477-483.

92. Kyrklund C, Backman JT, Kivistö KT, Neuvonen M, Laitila J, et al. (2000) Rifampin greatly reduces plasma simvastatin and simvastatin acid concentrations. Clin Pharmacol Ther 68(6): 592-597.

93. Superko R, Momary KM, Li Y (2012) Statins personalized. Med Clin N Am 96(1): 123-139.

94. Li ZL, Seeram NP, Lee R, Thames G, Minutti C, et al. (2005) Plasma clearance of lovastatin versus Chinese red yeast rice in healthy volunteers. Altern Compl Med 11(6): 1031-1038.

95. Gordon RY, Becker DJ (2011) The role of red yeast rice for the physician. Curr Atheroscler Rep 13(1): 73-80. 
96. Cesarone MR, Ledda A, Belcaro G, Ricci A, Stuard S, et al. (2010) Antilip $^{\square}$ :treatment of subject with high total cholesterol tolerability and efficacy in a short term registry study. Pan Med 52(2 suppl 1): 15-19.

97. Halbert SC, French B, Gordon RY, Farrar JT, Schmitz K, et al. (2010) Tolerability of red Yeast rice $(2,400 \mathrm{mg}$ twice daily) versus pravastatin (20 mg twice daily) in patients with previous statin intolerance. Am J Cardiol 105(2): 198-204.

98. Hua W, Ding L, Chen Y, Gong B, Jianchang He, et al. (2007) Determination of berberine in human plasma by liquid chromatography-electrospray ionization-mass spectrometry. J Pharm Biomed Anal 44(4) 931-937.

99. Pereira CV, Machado NG, Oliveira PJ (2008) Mechanism of berberine (natural yellow 18)-induced mitochondrial dysfunction: interaction with the adenine nucleotide translocator. Tox Sci 105(2): 408-417.

100. Mück W (2000) Clinical pharmacokinetics of cerivastatin. Clin Pharmacokinet 39(2): 99-116.

101. Morgan RE, Campbell SE, Yu CY (2012) Comparison of the safety, tolerability, and pharmacokinetics of a single oral dose of pitavastatin 4 mg in adult subjects with severe renal impairment not on hemodialysis versus healthy subjects. J Cardiovasc Pharmacol 60: 42-48.

102. Warrington S, Nakagawua S, Hounslow N (2011) Comparison of the pharmacokinetics of pitavastatin by formulation ethnic group. Clin Drug Invest 31(10): 736-743.

103. Wen J, Xiong Y (2010) OATP1B1 388A $>$ G polymorphism and pharmacokinetics of pitavastatin in Chinese healthy volunteers. J Clin Pharmacy Ther 35(1): 99-104.
104. Ando H, Tsuruoka S, Yanagihara H, Sugimoto K, Miyata M, et al. (2005) Effects of grapefruit juice on the pharmacokinetics of pitavastatin and atorvastatin. BJCP 60(5): 494-497.

105. Ieiri I, Suwannakul S, Maeda K, Uchimaru H, Hashimoto K, et al. (2007) SLC01B1 (OATP1B1, an uptake transporter) and ABCG2 (BCRP, an efflux transporter) variant alleles and pharmacokinetics of pitavastatin in healthy volunteers. Clin Pharmacol Ther 82(5): 541-547.

106. Chen Y, Zhang W, Huang W, Tan ZR, Wang YC, et al. (2013) Effect of a single-dose rifampicin on the pharmacokinetics of pitavastatin in healthy volunteers. Eur J Clin Pharmac 69(11): 1933-1938.

107. Oh OS, Co K, Cho SK, Park MS, Jae-Yong C, et al. (2012) Impact of ABCC2, ABCG", and SLC01B1 polymorphism on the pharmacokinetics of pitavastatin in humans. Drug Metab Pharmacokinet 28(3): 196202.

108. Hui CK, Cheung MY, Lau GKK (2004) Pharmacokinetics of pitavastatin in subjects with Child-Pugh A an B cirrhosis. Br J Clin Pharmacol 59(3): 291-297.

109. Hu M, Mak VWL, Yin OQP, Chu TT, Tomlinson B, et al. (2013) Effect of grapefruit juice and SLCOB1 388 $>$ G polymorphism on the pharmacokinetics of pitavastatin. Drug Metab Pharmacokinet 28(2): 104-108.

110. Catapano AL (2010) Pitavastatin-pharmacological profile from early phase studies. Atheroscler Suppl 11(3): 3-7.
Your next submission with Juniper Publishers will reach you the below assets

- Quality Editorial service

- Swift Peer Review

- Reprints availability

- E-prints Service

- Manuscript Podcast for convenient understanding

- Global attainment for your research

- Manuscript accessibility in different formats

( Pdf, E-pub, Full Text, Audio)

- Unceasing customer service

Track the below URL for one-step submission https://juniperpublishers.com/online-submission.php 